\title{
Is non-union of tibial shaft fractures due to nonculturable bacterial pathogens? A clinical investigation using PCR and culture techniques
}

\author{
Justus Gille ${ }^{1 *}$, Steffen Wallstabe ${ }^{2}$, Arndt-Peter Schulz ${ }^{1}$, Andreas Paech ${ }^{1}$ and Ulf Gerlach ${ }^{2}$
}

\begin{abstract}
Background: Non-union continues to be one of the orthopedist's greatest challenges. Despite effective culture methods, the detection of low-grade infection in patients with non-union following tibial fracture still presents a challenge. We investigated whether "aseptic" tibial non-union can be the result of an unrecognized infection.

Methods: A total of 23 patients with non-union following tibial shaft fractures without clinical signs of infection were investigated. Intraoperative biopsy samples obtained from the non-union site were examined by means of routine culture methods and by polymerase chain reaction (PCR) for the detection of $16 \mathrm{~S}$ ribosomal RNA (rRNA). Control subjects included 12 patients with tibial shaft fractures.

Results: 23 patients (8 women and 15 men; mean age: 47.4 years) were included into this study. Preoperative Creactive protein levels (mean: $20.8 \mathrm{mg} / \mathrm{l}$ ) and WBC counts (mean: 8,359/ $\mathrm{\mu l}$ ) in the study group were not significantly higher than in the control group. None of the samples of non-union routine cultures yielded microorganism growth. Bacterial isolates were found by conventional culturing methods in only 1 case of an open fracture from the control group. In this case, PCR yielded negative results. $16 \mathrm{~S}$ rRNA was detected in tissue specimens from 2 patients (8.7\%) with non-union. The analysis of these variable species-specific sequences enabled the identification of specific microorganisms (1x Methylobacterium species, 1x Staphylococcus species). Both PCR-positive patients were culture-negative.

Conclusions: The combination of microbiological culture and broad-range PCR seems to substantially add to the number of microbiological diagnoses obtained and may improve the clinican's ability to tailor therapy to the individual patient's needs.
\end{abstract}

Keywords: Non-union, Tibial fracture, Low-grade infection, Molecular diagnosis, PCR technique

\section{Article summary}

We investigated whether "aseptic" tibial non-union is related to unrecognized infection. 23 patients ( 8 women and 15 men; mean age: 47.4 years) were included in the study. $16 \mathrm{~S}$ rRNA was detected in 2 cases $(8.7 \%)$ of nonunion. PCR-positive patients were culture-negative in both cases.

\footnotetext{
* Correspondence: justus_gille@usa.net

${ }^{1}$ Department of Trauma and Reconstructive Surgery, University of SchleswigHolstein, Campus Luebeck, Luebeck, 23538, Germany

Full list of author information is available at the end of the article
}

\section{Introduction}

Diaphyseal tibia fractures are the most common lower limb fractures worldwide [1]. Despite advances in management, tibia fractures remain vulnerable to many complications, which often require secondary surgery. Potential complications include delayed union, nonunion, malunion, compartment syndrome and infection [2]. A recent study on open and closed diaphyseal tibia fractures treated by all modalities reported an overall revision rate of $22.4 \%$ [3], which was often the result of non-unions.

In about $10 \%$ of cases the healing process is delayed [4]; for certain at-risk patients, it can affect over 30\% [5]. Established causes of delayed union and non-union of 
tibial fractures are systemic deficits, e.g. advanced patient age [6] and diabetes mellitus [7]; prior local impairment of the extremity, e.g. chronic impairment of the soft tissues or blood circulation [8]; and characteristics involving the traumatic impact itself, e.g. fracture localization [9], degree of soft tissue damage [10] and bacterial contamination $[1,11]$.

Non-union, especially when infected, continues to be one of the greatest challenges in orthopedic surgery. After open reduction and internal fixation of tibial shaft fractures, the rate of superficial infection is up to $22 \%$ and deep infections occur in up to $15 \%$ [2], the latter of which can potentially lead to septic nonunion of the tibia. Clinical signs, laboratory investigations of infection parameters and microbiological findings are often insufficient for detecting infection. Distinguishing between infection and aseptic non-union is essential for determining the proper clinical course of action [12]. The standard analyses for detecting microorganisms - gram staining (for microscopic investigation) and culturing of tissue biopsy specimens obtained during surgical revision - are reported to have poor sensitivity [13]. The hypothesis is that evidence of bacterial infection is supported further by the detection of bacterial DNA, which suggests bacterial persistence in the area of non-union despite negative culture results. PCR targeting highly conserved regions of the bacterial genome (e.g. the $16 \mathrm{~S}$ rRNA gene) has been used successfully to detect nonculturable bacteria that cause a variety of infections, including septic arthritis [14] and meningitis [15]. The aim of this study was to investigate whether"aseptic" nonunion after tibial shaft fractures is due to nonculturable bacteria by means of PCR amplification of $16 \mathrm{~S}$ rRNA genes and to compare the efficiency of PCR with that of standard culture techniques.

\section{Materials and methods}

All patients participating in the present study were informed in detail about the surgical technique and all alternative procedures with their respective advantages and disadvantages, and all participants chose to undergo the index surgical procedure. All patients signed informed consent forms to participate in the study. The study was performed in accordance with the local ethical review board.

From November 2009 through March 2010, a consecutive series of 23 patients with non-union following tibial shaft fractures were investigated. Normal healing was defined as union within 4 months, delayed union as healing between 4 and 6 months and non-union was defined as the absence of healing after 6 months [16]. Only patients without clinical signs of infection were included in the study. Exemplary $x$-rays of one case from the treatment group are shown in Figure 1. Control subjects included 12 patients undergoing open reduction and internal fixation for acute tibial shaft fractures.

A stage-adapted treatment algorithm for tibial nonunion has been established, as previously published [16]. Based on contemporary evidence among the recent literature, we do not routinely administer antibiotics beyond 5 days postoperatively [17]. We favor oral antibiotic administration, because our experience has shown us that the route of antibiotic administration (oral versus parenteral) does not affect the rate of disease remission if the bacteria are sensitive to the antibiotic used.

All patients received standard preoperative care. Skin was decontaminated with Cutasept $\mathrm{H}$ (Bode Chemie, Germany). Two grams of cefazolin (Basocef, Deltaselect $\mathrm{GmbH}$, Germany) were administered for perioperative prophylaxis subsequent to taking the biopsies. Intraoperative biopsy samples (at least 3, each measuring $1 \mathrm{~cm}^{3}$ ) obtained from the non-union were all divided into 2 portions. Specimens were placed into separate sterile tubes without additional substrates. Specimens obtained for PCR were stored at $-70^{\circ} \mathrm{C}$. Samples were then examined by means of routine culture methods and by polymerase chain reaction (PCR) for the detection of $16 \mathrm{~S}$ ribosomal RNA (rRNA) in the laboratory. These procedures permitted the independent examination and interpretation of the results. Histopathologic findings were not recorded because of poor sensitivity, especially in cases of low-grade infection $[18,19]$.

\section{Bacterial isolation and standard culture methods}

All specimens were incubated in brain-heart infusion broth (bioMérieux, Nuertingen, Germany), TVLS medium [20], a medium described by Lodenkaemper and Stinen [21], on Columbia blood plates (aerobic 5\% $\mathrm{CO}_{2}$ ), and then on Brucella agar plates (anaerobic) (bioMérieux, Nuertingen, Germany), as previously described [12]. Samples were incubated for 14 days. Susceptibility testing was performed according to the German Institutional Standard Nr. 58940 [22].

\section{DNA isolation}

Tissue samples were immediately stored at $-70^{\circ} \mathrm{C}$, and DNA was purified from homogenized specimens after proteinase $\mathrm{K}$ digestion and column extraction with the NucleoSpin DNA kit (Macherey-Nagel, Dueren, Germany). All DNA procedures before and after PCR were performed in separate designated rooms with separate pipetting devices to avoid contamination of the samples with foreign DNA. Master-mixture water controls were used for every sample that was processed. 


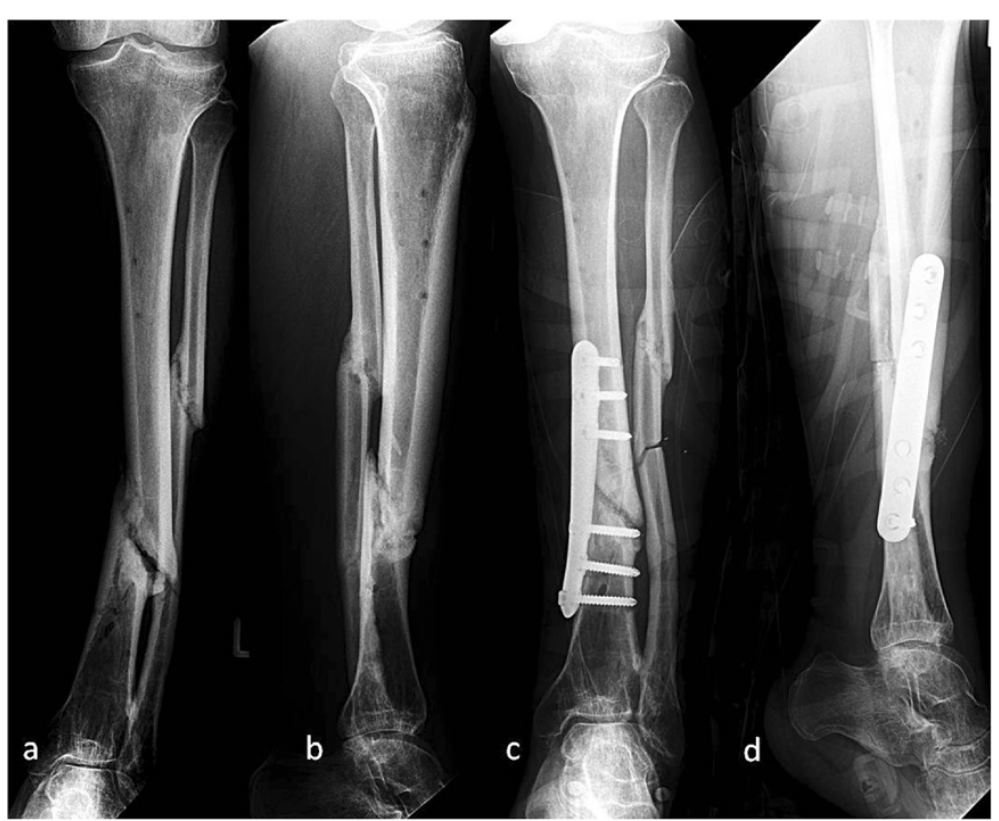

Figure 1 Consecutive $x$-rays of a 30-year-old male with tibial non-union and valgus malalignment following stabilization with external fixator for 6 months (Figures a,b). Postoperative findings after excision of necrotic tissue and re-osteosynthesis with a multidirectional locking plate (tifix ${ }^{\circledR}$-tibia-plate, Litos, Hamburg, Germany) in combination with reconstruction of skeletal defects by implantation of autologous bone removed from the iliac crest (Figures $c, d$ ). Conventional and molecular bacteria detection methods were both negative.

\section{PCR amplification}

The sequences of the universal primers (16rRNA gene) and primers of the control gene (glyceraldehydes-3phosphate dehydrogenase; GAPDH) are indicated in Table 1. Oligonucleotides used in this study were provided by Eurofins MWG Operon, Ebersberg, Germany. DNA was amplified in a $25 \mu \mathrm{L}$-reaction mixture consisting of ready-to-go PCR beads (up to $23 \mu \mathrm{L}$; Amersham Pharmacia Biotech, Muenchen, Germany), $0.5 \mu \mathrm{L}$ of each primer $(100 \mathrm{pmol} / \mathrm{mL})$, and $1 \mu \mathrm{L}$ of the sample. After amplification, $5 \mu \mathrm{L}$ of the amplified product was analyzed in a $2 \%$ agarose gel. Amplification products were sequenced by SeqLab and then analyzed using the National Center for Biotechnology Investigation Blast database $[23,24]$.

Table 1 Nucleotide sequences of primers used to determine agents responsible for non-union following tibial shaft fractures

\begin{tabular}{ll}
\hline Primer & Sequence \\
\hline 16S rRNA & \\
Forward & 5'-AGAGTTTGACCTGGCTCAG-3' \\
Reverse & 5'-CCCACTGCTGCCCGTAG-3' \\
GAPDH & \\
Forward & 5'-TCTGCCCCCTCTGCTGATGCCCCC-3' \\
Reverse & 5'-CCATCACGCCACAGTTCCCGGAG-3' \\
Note. GAPDH & Glyceraldehydes-3-phosphate dehydrogenase \\
\hline
\end{tabular}

Amplification of the GAPDH control gene was performed using real-time PCR (Light Cycler Detection System; Roche Molecular Biochemicals, Mannheim, Germany) with the FastStart DNA Master SYBR kit (Roche Molecular Biochemicals). The PCR protocol included the following work stages: $95^{\circ} \mathrm{C}$ for $10 \mathrm{~min}$, followed by 40 cycles at $95^{\circ} \mathrm{C}$ for $10 \mathrm{~s}, 60^{\circ} \mathrm{C}$ for $5 \mathrm{~s}$, and $72^{\circ}$ $\mathrm{C}$ for $10 \mathrm{~s}$. In the dissociation protocol, single peaks were confirmed to exclude nonspecific amplification.

\section{Statistical analysis}

Statistical analysis was performed with the Statistical Package for the Social Sciences (SPSS 15.0, Chicago, IL, USA) for descriptive statistics with a level of significance set at $p<0.05$. The non-parametric Wilcoxon's signed rank test was used to analyze the data.

\section{Results}

The experimental group of patients with tibial nonunion consisted of 8 women and 15 men, with a mean age of 47.4 years (range: $20-82$ years). The mean age of the control group was 49.3 years (range: $17-73$ years), including 2 females and 10 males.

The mean interval of the fracture to the index operation due to non-union was 10.2 months (range: 634 months). At the time of the initial trauma, 8 cases (34.8\%) were rated as open fractures due to severe soft tissue injuries according to the classification by Gustilo et al. [25]. Four open fractures (33.3\%) were counted in 


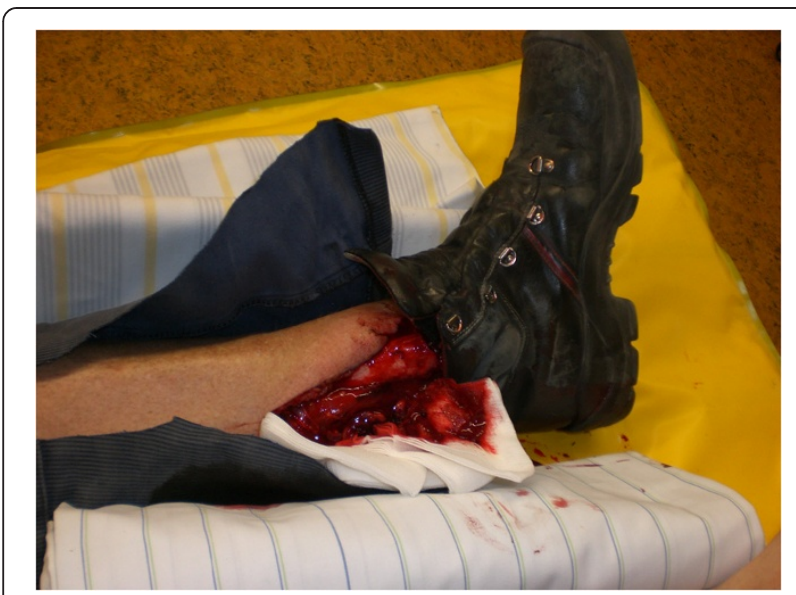

Figure 2 38-year-old male with an open tibial fracture (control group). This figure demonstrates the findings before the initial treatment. The isolated pathogens in culture were Streptococcus suis and Enterococcus species. Tissue from the fracture gap after initial débridement yielded negative results by PCR.

the control group. Up to 8 revision surgeries (mean: 1.9; range: $1-8$ ) had been performed in 18 cases (78.3\%) prior to the index operation.

For all patients in the experimental group, clinical pathological data - especially C-reactive protein levels (mean: $20.8 \mathrm{mg} / \mathrm{l}$; range: 1.6-92.7) and WBC counts $(8,359 / \mu \mathrm{l}$; range: $4,360-15,130)$ were not significantly higher compared to the control group (CRP: mean: $25.7 \mathrm{mg} / \mathrm{l}$; range: $2.9-133$, WBC: mean: $11,234 / \mu \mathrm{l}$; range: 6,110-17,210).

None of the non-union culture samples showed evidence of microorganism growth. Bacterial isolates were found by conventional culturing methods in only 1 case of an open fracture from the control group (Figure 2). The isolated pathogens were Streptococcus suis and Enterococcus species. Tissue from the fracture gap in this case after initial débridement yielded negative results by PCR.

$16 \mathrm{~S}$ rRNA was detected in tissue specimens from 2 cases $(8.7 \%)$ of non-union. Further analysis of these variable species-specific sequences enabled the identification of specific microorganisms; in one case Methylobacterium species and in the other sample Staphylococcus species were identified. The PCR-positive patients were both culture-negative.

\section{Discussion}

To the best of our knowledge, this is the first study on conventional and molecular bacteria detection methods in non-unions following tibia shaft fractures to validate the hypothesis that non-culturable microorganisms are a potential source of non-union.

Diaphyseal tibia fractures are the most common lower limb fractures worldwide [1]. There is controversy among the literature regarding the best way to manage open tibial shaft fractures. Recently, a metaanalysis of randomized prospective studies was performed comparing external fixators and unreamed IM nails. There was no statistically significant difference between the two methods of stabilization with respect to union, delayed union, deep infection and chronic osteomyelitis [26]. Non-union continues to be one of the orthopedist's greatest challenges, especially in its septic form.

As for many other infectious processes, early detection can often alter the natural course of the disease and ultimately improve long-term outcomes for patients [27]. There might be clinical signs highly suggestive of infection, but diagnosis can be a difficult task, particularly in the case of late and/or chronic infections [28].

Laboratory markers such as C-reactive protein, erythrocyte sedimentation rate, and white blood count are sensitive markers of inflammation and plausible infection, but they are unable to localize the exact site of infection and they are associated with low specificity [29]. In this series, no significant difference was obvious between the treatment and control group according to inflammatory laboratory markers, although the mean values in both groups diverged from the norm. Elevations in patients from the control group might have been due to trauma, which often leads to increased levels of laboratory markers in the absence of infection [30,31].

The standard analyses for detecting microorganisms gram staining (for microscopic investigation) and culturing of tissue biopsy specimens obtained during surgical revision - are reported to have poor sensitivity [12]. The sensitivity seems to be related to the amount of biopsies taken [32]. Antibiotics administered for perioperative prophylaxis, as well as extended transportation time, inadequate quantities of vital bacteria and preservation of specimens before processing may all lead to negative culture results [33].

Although there is a large body of evidence on wound bacteriology after open fractures [25] with positive culture results in up to $83 \%$ [34], the literature regarding infection in closed fracture gaps that affect healing is lacking [35]. In our series, none of the closed fractures in the control group were culture-positive.

Many molecular tools for bacterial DNA detection from clinical samples have been developed. One of the most significant contributions thus far has been amplification-based techniques (PCR), since some studies have confirmed its excellent sensitivity and specificity [27]. Moreover, the PCR technique takes less than 5 hours to complete, which is significantly shorter than the couple of days required for routine cultures. In a prospective study comparing PCR and culture techniques in the diagnosis of prosthetic joint infection, Gallo et al. 
demonstrated a significantly higher sensitivity, accuracy and negative predictive value for PCR versus culture [13]. There was $83 \%$ concordance between the results of intraoperative culture and PCR detection of causative bacteria [13]. This is in accordance with Hoeffel et al., who reported a PCR sensitivity and specificity of $71 \%$ and $49 \%$, respectively, and a positive predictive value of $22 \%$ and a negative predictive value of $7 \%$, when compared with culture methods [36]. The authors concluded that the PCR methods should not serve as screening tests for musculoskeletal infections, but they could be useful to confirm infections, especially after initiating antibiotic treatment. Shortcomings of the PCR technique compared to routine cultures are higher costs, false-positive results and problems with interpretation [27].

In our series, $16 \mathrm{~S}$ rRNA was detected in tissue specimens from 2 cases $(8.7 \%)$ of non-union. In contrast to our results, Szczèsny et al. report the presence of bacteria in the callus of closed fractured bones in up to $42 \%$ [37]. Both viable bacteria and their DNA were detected. Interestingly, the majority of isolates were not detected in the fracture gap tissue but in the subcutaneous tissue and muscles. In patients with nonalignment, S. epidermidis and aureus were detected in 4 out of 24 patients, whereas in the delayed healing group bacterial isolates were found in 15 out of 43 patients [37]. The reasons for the diversity between their results and ours remain unclear, although one can pinpoint the fact that in the present study, tissue from non-unions was investigated. In addition, the results of $16 \mathrm{~S}$ PCR are known to be very susceptible for contamination. Our tests were performed under sterile conditions in a laboratory room designated for RNA isolation and identification only. Sodium chloride solution used for tissue samples was checked for the presence of $16 \mathrm{~S}$ rRNA and was found to be negative for all samples. Further, most authors consider the positive cultures of deep tissue specimens to be contamination from external sources [38]. Contamination of specimens could be precluded from being the source of detected isolates.

There are two limitations that need to be acknowledged and addressed regarding the present study. The first limitation concerns the heterogeneous patient population, which reflects the situation of patients with tibial non-union. The second limitation involves the extent to which the findings can be generalized beyond the cases studied. The number of cases is too small for broad generalizations. However, these limitations can be seen as fruitful avenues for future research along the same lines.

This is the first study comparing routine cultures and molecular bacterial DNA detection in tibial non-union. In summary, nonculturable pathogens seem to play a causative role in tibial non-unions. The combination of microbiological culture and broad-range PCR seems to substantially add to the number of microbiological diagnoses obtained and may improve the clinican's ability to tailor therapy to the individual patient's needs.

\section{Competing interests}

The authors declare that they have no competing interests. None of the authors received financial support.

\section{Authors' contributions}

1. Conception and design of the study: JG, UG 2, Analysis and interpretation of data: SW, AP, AS, JG 3, Collection and assembly of data: SW, AP, UG, AS, JG 4, Drafting of the article: JG, UG. All authors read and approved the final manuscript.

\section{Acknowledgements}

The authors thank Jan Rupp, PhD, for his support and the opportunity to perform the PCR in his laboratory.

We gratefully acknowledge the skilled technical assistance of Ms. Angela Gravenhorst and Mr. Stefan Bark.

None of the authors received financial support.

\section{Author details}

'Department of Trauma and Reconstructive Surgery, University of SchleswigHolstein, Campus Luebeck, Luebeck, 23538, Germany. ${ }^{2}$ Department of Trauma Surgery and Sportsmedicine, BG-Traumahospital Hamburg, Hamburg, 21033, Germany.

Received: 23 December 2010 Accepted: 2 May 2012

Published: 20 May 2012

\section{References}

1. Harris I, Lyons M: Reoperation rate in diaphyseal tibia fractures. ANZ J Surg 2005, 75:1041-1044.

2. Littenberg B, Weinstein LP, McCarren M, Mead T, Swiontkowski MF, Rudicel $S A$, Heck D: Closed fractures of the tibial shaft. A meta-analysis of three methods of treatment. J Bone Joint Surg Am 1998, 80:174-183.

3. Bhandari M, Guyatt GH, Swiontkowski MF, Schemitsch EH: Treatment of open fractures of the shaft of the tibia. J Bone Joint Surg Br 2001, 83:62-68.

4. Einhorn TA: The cell and molecular biology of fracture healing. Clin Orthop Relat Res 1998, 355:S7-S21.

5. Rothman $\mathrm{RH}$, Klemek JS, Toton JJ: The effect of iron deficiency anemia on fracture healing. Clin Orthop Relat Res 1971, 77:276-283.

6. Tonnesen PA, Heerfordt J, Pers M: 150 open fractures of the tibial shaftthe relation between necrosis of the skin and delayed union. Acta Orthop Scand 1975, 46:823-835.

7. Macey LR, Kana SM, Jingushi S, Terek RM, Borretos J, Bolander ME: Defects of early fracture-healing in experimental diabetes. J Bone Joint Surg Am 1989, 71:722-733.

8. Spector JA, Mehrara BJ, Greenwald JA, Saadeh PB, Steinbrech DS, Bouletreau PJ, Smith LP, Longaker MT: Osteoblast expression of vascular endothelial growth factor is modulated by the extracellular microenvironment. Am J Physiol Cell Physiol 2001, 280:C72-C80.

9. Nelson GE Jr, Kelly PJ, Peterson LF, Janes JM: Blood supply of the human tibia. J Bone Joint Surg Am 1960, 42-A:625-636.

10. Brinker MR, Bailey DE Jr: Fracture healing in tibia fractures with an associated vascular injury. J Trauma 1997, 42:11-19.

11. Kienast B, Kiene J, Gille J, Thietie R, Gerlach U, Schulz AP: Posttraumatic severe infection of the ankle joint - long term results of the treatment with resection arthrodesis in 133 cases. Eur J Med Res 2010, 15:54-58.

12. Ince A, Rupp J, Frommelt L, Katzer A, Gille J, Lohr JF: Is "aseptic" loosening of the prosthetic cup after total hip replacement due to nonculturable bacterial pathogens in patients with low-grade infection? Clin Infect Dis 2004, 39:1599-1603.

13. Gallo J, Kolar M, Dendis M, Loveckova Y, Sauer P, Zapletalova J, Koukalova D: Culture and PCR analysis of joint fluid in the diagnosis of prosthetic joint infection. New Microbiol 2008, 31:97-104.

14. Ince A, Tiemer B, Gille J, Boos C, Russlies M: Total knee arthroplasty infection due to Abiotrophia defectiva. J Med Microbiol 2002, 51:899-902. 
15. Ni H, Knight Al, Cartwright K, Palmer WH, McFadden J: Polymerase chain reaction for diagnosis of meningococcal meningitis. Lancet 1992, 340:1432-1434.

16. Meiners J, Gerlach U, Magerlein S, Jurgens C, Faschingbauer M: Pseudoarthroses. Chirurg 2009, 80:979-986.

17. Conterno LO, da Silva Filho CR: Antibiotics for treating chronic osteomyelitis in adults. Cochrane Database Syst Rev 2009, CD004439.

18. Frommelt $L$ : Aspiration of joint fluid for detection of the pathogen in periprosthetic infection. Orthopade 2008, 37:1027-1034. quiz 1035-1026.

19. Milgram JW: Nonunion and pseudarthrosis of fracture healing. A histopathologic study of 95 human specimens. Clin Orthop Relat Res 1991, 268:203-213.

20. Caselitz FHFV: Halbflüssiges Kombinationsmedium zur Züchtung anaerober Bakterien. Aerztl Lab 1969, 15:426-430.

21. Lodenkamper H, Stienen G: Therapy of anaerobic infections. Dtsch Med Wochenschr 1956, 81:1226.

22. Edelmann A, Pietzcker T, Wellinghausen N: Comparison of direct disk diffusion and standard microtitre broth dilution susceptibility testing of blood culture isolates. J Med Microbiol 2007, 56:202-207.

23. Bednarski AE, Elgin SC, Pakrasi HB: An inquiry into protein structure and genetic disease: introducing undergraduates to bioinformatics in a large introductory course. Cell Biol Educ 2005, 4:207-220.

24. Thompson SM: Constructing and refining multiple sequence alignments with PileUp, SeqLab, and the GCG suite. Curr Protoc Bioinformatics 2003, doi:10.1002/0471250953.bi0306s00. Chapter 3:Unit 36.

25. Gustilo RB, Anderson JT: JSBS classics. Prevention of infection in the treatment of one thousand and twenty-five open fractures of long bones. Retrospective and prospective analyses. J Bone Joint Surg Am 2002, 84-A:682.

26. Giannoudis PV, Papakostidis $C$, Roberts $C:$ A review of the management of open fractures of the tibia and femur. J Bone Joint Surg Br 2006, 88:281-289

27. Gallo J, Raska M, Dendis M, Florschutz AV, Kolar M: Molecular diagnosis of prosthetic joint infection. A review of evidence. Biomed Pap Med Fac Univ Palacky Olomouc Czech Repub 2004, 148:123-129.

28. Schulz AP, Faschingbauer M, Seide K, Schuemann U, Mayer M, Jurgens C, Wenzl M: Is the Wave Plate Still a Salvage Procedure for Femoral Nonunion? Results of 75 Cases Treated with a Locked Wave Plate. Eur J Trauma Emergency Surgery 2009, 35:127-131.

29. Virolainen $P$, Lahteenmaki H, Hiltunen A, Sipola E, Meurman O, Nelimarkka $\mathrm{O}$ : The reliability of diagnosis of infection during revision arthroplasties. Scand J Surg 2002, 91:178-181.

30. Amara U, Kalbitz M, Perl M, Flierl MA, Rittirsch D, Weiss M, Schneider M, Gebhard F, Huber-Lang M: Early expression changes of complement regulatory proteins (CRegs) and C5a receptor (CD88) on leukocytes after multiple injury in humans. 2009, Shock.

31. Knesek MJ, Litinas E, Adiguzel C, Hopkinson W, Hoppensteadt D, Lassen M, Fareed J: Inflammatory biomarker profiling in elderly patients with acute hip fracture treated with heparins. Clin Appl Thromb Hemost, 16:42-50.

32. Oheim R, Gille J, Schoop R, Magerlein S, Grimme CH, Jurgens C, Gerlach UJ: Surgical therapy of hip-joint empyema. Is the Girdlestone arthroplasty still up to date? Int Orthop.

33. Trampuz A, Osmon DR, Hanssen AD, Steckelberg JM, Patel R: Molecular and antibiofilm approaches to prosthetic joint infection. Clin Orthop Relat Res 2003, :69-88.

34. Robinson D, On E, Hadas N, Halperin N, Hofman S, Boldur I: Microbiologic flora contaminating open fractures: its significance in the choice of primary antibiotic agents and the likelihood of deep wound infection. J Orthop Trauma 1989, 3:283-286.

35. Swinson BD, Morrison CM, Sinclair JS: Pyoderma gangrensum-a complication of breast biopsy. Ulster Med J 2002, 71:66-67.

36. Hoeffel DP, Hinrichs SH, Garvin KL: Molecular diagnostics for the detection of musculoskeletal infection. Clin Orthop Relat Res 1999, 360:37-46.

37. Szczesny G, Interewicz B, Swoboda-Kopec E, Olszewski WL, Gorecki A, Wasilewski P: Bacteriology of callus of closed fractures of tibia and femur. J Trauma 2008, 65:837-842.

38. Vehmeyer SB, Slooff AR, Bloem RM, Petit PL: Bacterial contamination of femoral head allografts from living donors. Acta Orthop Scand 2002. 73:165-169.
doi:10.1186/1749-799X-7-20

Cite this article as: Gille et al.: Is non-union of tibial shaft fractures due to nonculturable bacterial pathogens? A clinical investigation using PCR and culture techniques. Journal of Orthopaedic Surgery and Research 2012 7:20.

\section{Submit your next manuscript to BioMed Central and take full advantage of:}

- Convenient online submission

- Thorough peer review

- No space constraints or color figure charges

- Immediate publication on acceptance

- Inclusion in PubMed, CAS, Scopus and Google Scholar

- Research which is freely available for redistribution 